\title{
Erratum to: Identifying multiple eruption phases from a compound tephra blanket: an example of the AD1256 Al-Madinah eruption, Saudi Arabia
}

\author{
E. Kawabata $\cdot$ S. J. Cronin $\cdot$ M. S. Bebbington • \\ M. R. H. Moufti • N. El-Masry • T. Wang
}

Published online: 3 March 2015

(C) Springer-Verlag Berlin Heidelberg 2015

Erratum to: Bull Volcanol (2015) 77: 6

DOI 10.1007/s00445-014-0890-y

It has been drawn to our attention that the simple calculation of volume from the naïve isopachs (Fig. 2) by means of the Pyleogram contains an error (a factor of pi). The actual volume thus calculated should be $0.0077 \mathrm{~km}^{3}$. This error is not propagated into the remainder of the analysis, where volumes were calculated via direct numerical integration from the contours imputed from our model (Fig. 12). These are far more extensive than those in Fig. 2, particularly in the West, East and especially South directions. Hence the volume calculated for these is approximately a factor of 3 larger.

The online version of the original article can be found at http://dx.doi.org/ 10.1007/s00445-014-0890-y.

E. Kawabata $(\bowtie) \cdot$ S. J. Cronin $\cdot$ M. S. Bebbington

Volcanic Risk Solutions, Massey University, Private Bag 11222,

Palmerston North 4442, New Zealand

e-mail: e.kawabata@massey.ac.nz

M. R. H. Moufti $\cdot$ N. El-Masry

Faculty of Earth Sciences, King Abdulaziz University,

P.O. Box 80200, Jeddah 21589, Saudi Arabia

T. Wang

Department of Mathematics and Statistics, University of Otago,

P.O. Box 56, Dunedin 9054, New Zealand 